Check for updates

Cite this: Mater. Adv., 2020 1,1775

Received 1st June 2020, Accepted 15th July 2020

DOI: $10.1039 / \mathrm{d} 0 \mathrm{ma} 00367 \mathrm{k}$

rsc.li/materials-advances

\section{Cancer cell membrane-derived nanoparticles improve the activity of gemcitabine and paclitaxel on pancreatic cancer cells and coordinate immunoregulatory properties on professional antigen-presenting cells $\dagger$}

\author{
Edson J. Comparetti, (D) * Paula M. P. Lins, (D) João V. B. Quitiba and \\ Valtencir Zucolotto (iD *
}

\begin{abstract}
Human pancreatic carcinoma is among the neoplasias with the highest number of deaths, and the frequency of relapses has demanded novel therapeutic intervention. Currently, the simultaneous application of different chemotherapeutics improves treatment efficiency in patients. However, the low specificity of these molecules may increase the cytotoxic side effects in healthy cells. Nanocarriers conjugated with aptamers and monoclonal antibodies target distinct proteins expressed on cancer cells and can be used to increase drug activity in disease sites. A recent advance in nanoengineering has led to the isolation of cell membrane lipids and proteins from cytoplasmatic organelles by ultracentrifugation, and the double-layer surface is used to coat organic and inorganic nanoparticles to prolong their permanence in the bloodstream. Additionally, plasmatic cell components form lipid nanovesicles that can deliver antineoplastic molecules. The present study aims to isolate the major components from pancreatic tumor cell membranes (PANC-1) to fabricate nanoparticles (MNPs) encapsulating two first-line drugs used in clinical treatment, viz., gemcitabine (GEM) and paclitaxel (PTX). Our results demonstrate that the MNP-GEM-PTX are very stable and induce greater cytotoxic effects on PANC-1 cells, in comparison to the use of pure GEM+PTX. The most interesting finding is that MNPs also interact with monocytes and dendritic cells, increasing the expression of costimulatory molecules CD80, CD83, CD86, and HLA-DR, indicating that the drug-carrier property of MNPs upregulates the activation of white blood cells. Therefore, a novel class of nanoparticles has been used to deliver antineoplastic agents to cancer cells and antigenic material to antigen-presenting cells. We also investigated their ability to modulate immune cells, aiming to promote pro-inflammatory responses in tumor sites.
\end{abstract}

\section{Introduction}

Chronic diseases are responsible for $15 \%$ of deaths worldwide, ${ }^{1}$ with 9.5 million casualties registered in 2018 and 17 million new cases expected for $2020 .^{2}$ Pancreatic cancer represents the 14th most frequent and the 7th highest mortality amid neoplasms, with diagnosis usually confirmed in the late stages when the disease has already progressed in the organism., Surgery and chemotherapy are the main therapeutic strategies against abnormal cells in the pancreas but patients survive for just a couple of months after initiating the treatments. ${ }^{3,4}$

Nanomedicine and Nanotoxicology Group, Physics Institute of São Carlos, University of São Paulo, São Carlos, SP, Brazil. E-mail: zuco@ifsc.usp.br, edsoncomparetti@usp.br

$\dagger$ Electronic supplementary information (ESI) available. See DOI: 10.1039/d0ma00367k
In chemotherapy, the most common classes of drugs include alkylates to inhibit DNA transcription, antimetabolites - cellular compound analogs - that block metabolic pathways in the $S$-phase, microtubule-stabilizing agents in the $\mathrm{G}_{0} / \mathrm{G}_{1}$ and/or $\mathrm{G}_{2} / \mathrm{M}$ phases, and topoisomerase inhibitors. ${ }^{5}$ Gemcitabine (GEM) is an antimetabolite drug used to treat pancreatic cancer because it interferes in DNA replication, inhibiting deoxyribonucleotide synthesis in the S-phase which lead to anti-cancer effects during cell division. In the late stages, pancreatic carcinoma is highly resistant to chemotherapy ${ }^{6}$ and to improve treatment efficiency, researchers have pointed to the simultaneous application of different drugs, such as the combination of GEM with cisplatin, oxaliplatin, taxol, and capecitabine. However, only therapies using GEM+Taxol demonstrated effects better than monotherapy with GEM in clinical trials. ${ }^{7}$ Simultaneous administration of GEM and paclitaxel (PTX) increases the survival rate by at least 2 months in 
patients with metastases, ${ }^{8}$ being considered a novel therapeutic procedure for pancreatic cancer.

Recent studies revealed the feasibility of nanoparticles (NPs) to deliver a high concentration of drugs within target cells and to reduce undesirable toxicity in other tissues. Nanoparticles can carry antineoplastic agents to improve drug activity in diseased cells, however, their applicability depends on their ability to move through organs and tissues in the human body. ${ }^{9}$ The "addressing" of primary and metastatic sites is done upon coupling antibodies and aptamers on the nanostructure surface, establishing greater specificity for target tissues. ${ }^{10}$ Such a strategy increases hydrophobic drug release in disease sites and minimizes the bioavailability to healthy cells. Nanomaterials also inhibit the expulsion of chemotherapeutic molecules from the cytoplasm by ATP carrier proteins (ABC transporters) before producing any cytotoxic effects. ${ }^{11}$ Liposomes used in drug delivery may reduce the hematological and vascular toxicity observed in clinical treatments with chemotherapeutics, restoring the normal levels of platelets, monocytes and T cells. ${ }^{12,13}$

A recent breakthrough in nanoengineering uses the major components from the cell membrane to camouflage nanostructures in the organism and to conduct their activity to the cells where the membrane residues came from. ${ }^{14}$ In the latter strategy, lipids and proteins are isolated by ultracentrifugation and are used to synthesize nanovesicles with immunomodulatory properties. ${ }^{15}$ Currently, studies already use lipids and proteins from the plasma membrane (MNPs) from red cells, immune cells (macrophages, dendritic cells, and $\mathrm{T}$ cells), and cancer cells in the preparation of nanostructures. The presence of cellular adhesion proteins aids interactions with the desired target cells ${ }^{\mathbf{1 4 , 1 6}}$ and membrane lipids (phospholipids, glycolipids, and cholesterol), increasing their stability in biological medium and keeping drugs bioavailable for weeks in the circulatory system. ${ }^{17-19}$

Neoplastic cell growth and expansion begin with their ability to modulate the tumor microenvironment and evade immune surveillance. To use nanoparticles in clinical treatments, it is necessary to investigate their toxicity and phenotypic changes in leukocytes from human peripheral blood. Nanocomposites prevent the production of immunosuppressive cytokines and increase the activity of the main mechanisms of cellular immunity. In this study, we synthesized lipid nanoparticles with the main components from the pancreatic cancer cell membrane (PANC-1) to deliver a large amount of antigenic material to antigenpresenting cells (APCs). The nanoparticles also carried low doses of GEM and PTX to reduce minimal effective doses in malignant cells and side effects in healthy cells. According to our knowledge, this is the first study using this class of nanovesicle to simultaneously deliver two chemotherapeutic drugs. Novel therapeutic approaches administer low and ultra-low doses of chemotherapeutics to inhibit the negative side effects in the organism, like severe immunosuppression and cancer resistance. ${ }^{20}$ Metronomic therapy has become more attractive than the periodic application of maximum tolerated doses because it reduces the immune suppression of macrophages and lymphocytes in the tumor microenvironment, activating white blood cells against neoplasias. ${ }^{21-23}$ The MNPs prepared

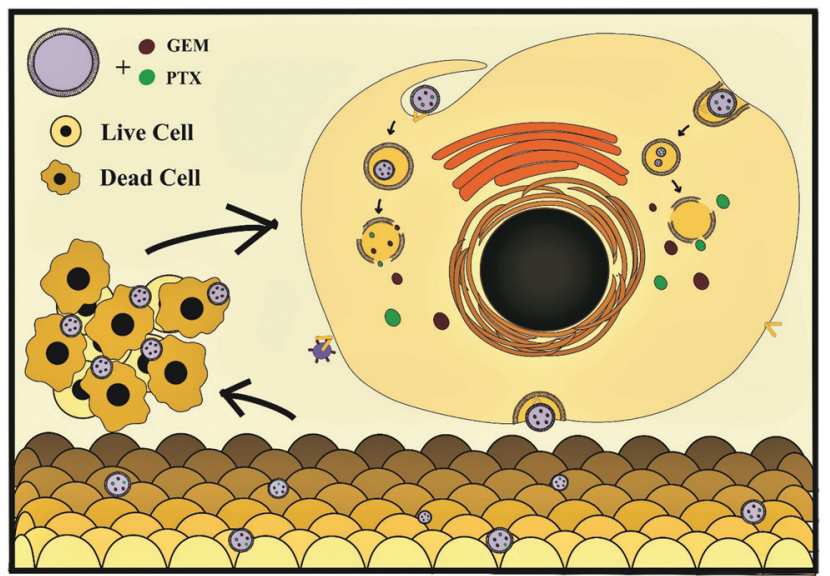

Scheme 1 Cancer cell membrane-derived nanoparticles target tumor sites and deliver gemcitabine (GEM), paclitaxel (PTX) chemotherapeutics and antigenic materials to immunosuppressed professional antigen-presenting cells.

here were tested in vitro in tumor and healthy cell lines to verify the cytotoxic activity of GEM/PTX nanocarriers (MNP-GEM-PTX) (Scheme 1). The ability of the nanoparticles to target specific cells was investigated by exposing them to PANC-1 cells, HEPA-RG cells and peripheral blood monocytes from healthy donors. We observed the excellent stability of MNP-GEM-PTX, which exhibited higher cytotoxic effects than GEM or PTX alone. Therefore, we set out to improve the drug delivery to pancreatic cells and improve antigenic material processing into monocytes and dendritic cells using nanovesicles created from cancer cell membrane components.

\section{Methodology}

\subsection{Nanoparticle synthesis}

Plasma membranes from pancreatic carcinoma cells were isolated by ultracentrifugation, as described by Lung et al., ${ }^{24}$ and extruded 20 times through a $100 \mathrm{~nm}$ membrane for nanovesicle fabrication. Briefly, the cells were detached from culture bottles, washed three times with PBS, lysed in a hypotonic buffer for $20 \mathrm{~min}$ at $4{ }^{\circ} \mathrm{C}$ and homogenized. The lysed cells were centrifuged at $15000 \mathrm{~g}$ for $15 \mathrm{~min}$ at $4{ }^{\circ} \mathrm{C}$ to remove cell debris. The supernatant was collected and centrifuged at $100000 \mathrm{~g}$ for $2 \mathrm{~h}$, using an Optima MAX-XP ultracentrifuge (Beckman Coulter, USA). The pellet containing the cell membranes was dispersed in $1 \mathrm{ml}$ of PBS containing Complete Protease Inhibitor (Roche Diagnostics, Mannheim, Germany) and stored at $-80{ }^{\circ} \mathrm{C}$. Membrane proteins present in the vesicles were quantified by the Bradford colorimetric assays (Sigma-Aldrich) to determine the protein concentration in the samples.

\subsection{Ultraviolet-visible spectroscopy (UV-Vis) and Fourier-transform infrared spectroscopy (FTIR)}

A Hitachi UV-Vis spectrophotometer, model U2008, was used to monitor the amount of chemotherapeutic agent encapsulated in MNPs and also its release over $48 \mathrm{~h}$. FTIR analyses were performed in a Nicolet iS-50 spectrophotometer. 


\subsection{Microscopy Analyses}

Nanoparticle morphology was analyzed using Field Emission Scanning Electron Microscopy (MEV-FEG, ZEISS, model SIGMA), Transmission Cryo-Electron Microscopy (TEM, JEOL 1400) and Atomic Force Microscopy (AFM, Nanosurf model EasyScan 2 FlexAFM) to measure the external density and dimensions, as well as to verify the presence of adsorbed or incorporated materials. Confocal microscopy (Leica TCS SP8) was also used to evaluate the nanoparticle interaction with the cells.

\subsection{Nanoparticle stability in aqueous solutions}

Dynamic light scattering (DLS) and zeta potential (spectrometer Zetasizer Nano ZS90) were used to evaluate nanoparticle polydispersity, size distribution, and surface potential. Nanoparticle tracking analysis (NTA) was carried out using a Malvern NanoSight NS300 instrument to also study nanoparticle size. DLS analyses were employed to evaluate the stability of the nanoparticles incubated in DMEM culture medium with $10 \%$ Fetal Bovine Serum (FBS) under agitation for $4 \mathrm{~h}, 8 \mathrm{~h}, 12 \mathrm{~h}, 24 \mathrm{~h}, 36 \mathrm{~h}$, and $48 \mathrm{~h}^{25}$

\subsection{Incorporation of chemotherapeutic drugs into MNPs}

Gemcitabine (GEM) and paclitaxel (PTX) were co-extruded with the hepatocellular carcinoma membranes through a $100 \mathrm{~nm}$ polycarbonate membrane using a mini-extruder (Avanti Polar Lipids). MNP-GEM and MNP-PTX were prepared by mixing $1 \mathrm{ml}$ of MNPs suspension at $10^{9}$ particle per ml with $5.2 \mu \mathrm{l}$ of GEM at $100 \mu \mathrm{M}$ and $7.12 \mu \mathrm{l}$ of PTX at $5 \mathrm{nM}$ dissolved in PBS and extruded through a $100 \mathrm{~nm}$ membrane in a Malvern nanoextruder at room temperature. The solution was centrifuged at $100000 \mathrm{~g}$ for $2 \mathrm{~h}$ and washed with PBS. After the removal of unloaded GEM and PTX, the complexes (MNP-GEM, MNP-PTX, and MNP-GEM-PTX) were re-suspended in $1 \mathrm{ml}$ of PBS under gentle sonication for $30 \mathrm{~min}$ at $40 \mathrm{kHz}$. UV/visible spectroscopy was carried out on pure MNPs and samples with GEM/PTX to estimate the amount of encapsulated chemotherapic molecules.

\subsection{MNPs staining with fluorescein isothiocyanate and analysis of their interaction with cells}

Nanovesicle labels were prepared by dispersing $10^{10}$ particles in $1 \mathrm{ml}$ of PBS and $0.1 \mathrm{mg}$ of fluorescein isothiocyanate (FITC), stirring in the dark at $4{ }^{\circ} \mathrm{C}$ for $12 \mathrm{~h}$. MNP-FITC was separated from unconjugated fluorescein by dialysis for $12 \mathrm{~h}$ on a $12 \mathrm{k}$ Dalton membrane. The suspension was ultracentrifuged and resuspended in PBS. FITC $^{+}$nanoparticles were used to prove the preferential uptake of MNPs by mononuclear cells (monocytes) and pancreatic cancer cells (PANC-1), and incubated with $10^{8}$ particles per $\mathrm{ml}$ for $48 \mathrm{~h}$. Flow cytometry (model FACS Calibur) was used to analyze the samples and the results were processed using the FlowJo software, version vX. 10.6.

\subsection{Tumor cell culture}

Pancreatic cancer cells (PANC-1) and hepatic cell lines (HEPA-RG) were cultured in complete medium [DMEM medium supplemented with $10 \%$ fetal bovine serum (FBS), 1\% sodium pyruvate, 1\% non-essential amino acids, $1 \%$ antibiotic and antimycotic
(Life Technologies), and HEPES (Sigma)] at $37{ }^{\circ} \mathrm{C}$ under $5 \%$ of $\mathrm{CO}_{2}$. We used $0.05 \%$ trypsin-EDTA (Gibco) to release cells from the bottle surface before washing in complete culture medium for use in the assays.

\subsection{Cytotoxicity assay (MTT)}

We analyzed the nanoparticle interactions with the cell lines using MTT (3-[4,5-dimethyl-thiazol-2-yl]-2,5-diphenyltetrazolium bromide) colorimetric assay. This salt was reduced to formazan crystals through mitochondrial metabolism, reflecting the activity of living cells as an indicator of viability. The treatment was performed by adding the particles and chemotherapeutics to cell culture $\left(1 \times 10^{4}\right.$ cells per well) in a flat-bottom plate of 96 wells for 24 and $48 \mathrm{~h}$. As contrasts we tested (a) pure MNPs; (b) MNPs encapsulated with GEM (MNP-GEM); (c) MNPs with PTX (MNP-PTX); (d) MNPs carrying GEM and PTX (MNP-GEM-PTX) and (d) pure GEM and PTX. Cells exposed to DMSO were used as the positive control in the assay (maximal lysis). The living cells were incubated with a solution of MTT for $3 \mathrm{~h}$ at $37{ }^{\circ} \mathrm{C}$ under $5 \%$ of $\mathrm{CO}_{2}$. Dimethyl sulfoxide (DMSO) solubilized formazan crystals in the mitochondria for analysis in the spectrophotometer at $580 \mathrm{~nm}$.

\subsection{Necrosis and apoptosis assays}

Flow cytometry confirmed the cytotoxic activity of MNPs at $10^{8}$ particles per $\mathrm{ml}$ and $10 \mu \mathrm{M}$ GEM and $10 \mathrm{nM}$ PTX. After incubation for $48 \mathrm{~h}$ in 12 -well plates, the particles were removed from the supernatant, as well as the cell debris. About $1 \times$ $10^{5}$ cells were collected and centrifuged at $10000 \mathrm{rpm}$ for 30 seconds and re-suspended in isoton (PBS, containing 0.5\% BSA) for 20 min at room temperature with Annexin V and 7AAD and analyzed by flow cytometry.

\subsection{Human monocytes culture}

Human monocytes were obtained from the peripheral blood of 3 healthy donors with ages ranging from 20 to 40 years. The investigation was carried out according to the Helsinki Declaration and approved by the Institutional Research Ethics Committee. All the cell donors were informed about the procedures, objectives and risks involved in the study, and signed an agreement form. Human peripheral blood monocytes were separated from red blood cells and plasma by centrifugation at $1600 \mathrm{rpm}$ for $35 \mathrm{~min}$ in the Ficoll-Isopaque gradient. The cell suspension was centrifuged in 51\% of Percoll gradient to separate monocytes from lymphocytes and dispense mononuclear cells into sterile plates $\left(2 \times 10^{5}\right.$ per well $)$ for performing the interaction assays.

\subsection{Dendritic cell differentiation}

Monocytes from healthy donors were differentiated in dendritic cells (DCs) after being supplemented in culture medium with $80 \mathrm{ng} \mathrm{ml}^{-1}$ of IL-4 and GM-CSF. The positive control group $\left(\mathrm{Control}^{+}\right)$was incubated with an activation cocktail composed of IL-1, IL6, TNF, and $\mathrm{PGE}_{2}$ to obtain complete mature DCs differentiation. After 6 days, adherent cells were harvested and washed with complete medium, being concentrated to $2 \times 10^{5}$ per well. DCs were treated with nanoparticles carrying antineoplastic agents to evaluate the cell viability, phenotype, and functional assays. 


\subsection{Evaluation of monocytes and the DC phenotype after} exposure to MNPs

We used flow cytometry to analyze surface markers from monocytes and dendritic cells after $48 \mathrm{~h}$ of treatment with monoclonal antibodies (BD Bioscience). In monocyte (CD14 ${ }^{+}$) and DC populations $\left(\mathrm{CD} 11 \mathrm{c}^{+}\right)$, we observed co-stimulation molecules (CD80, CD83, and CD86), major histocompatibility complex class II (HLA-DR), suppressor molecules (PD-L1) and cell viability $\left(7 \mathrm{AAD}^{+}\right)$, with analysis based on quadrant gates of working groups.

\subsection{Mixed lymphocyte reaction (MLR)}

Mixed Lymphocyte Reaction (MLR) investigates the DCs allogeneic response in lymphocyte proliferation. On the 7th day of differentiation, DCs treated with the previously described nanoparticles were co-cultured with lymphocytes. In experiments of allogeneic response, the ratio of $1: 10$ between DCs and lymphocytes was used. The culture was maintained for 5 days and the total of the allogeneic lymphocytes incubated with MTT salt at the end of the period was determined for proliferative analysis.

\subsection{Statistical analysis}

All assays were repeated at least 3 times and data analysis was submitted to ANOVA, followed by Tukey Mean Difference tests, considering differences with error probability less than or equal to $5 \%(\alpha \leq 0.05)$.

\section{Results}

\subsection{Nanoparticle characterization}

The plasma membrane-derived nanoparticles were produced by extrusion after membrane extraction from the pancreatic cancer cell line (PANC-1). Dynamic light scattering and nanoparticle tracking analysis revealed particles with an average size between 100-200 nm. All nanoparticles exhibited negative zeta potential when dispersed in PBS at pH 7.4. However, in buffer solution at pH 4.4, only the experimental groups encapsulated with PTX presented a negatively superficial charge (Table 1). A negative charge was expected since the MNP contained antigenic material from PANC-1 in phospholipid bilayers. For example, the MNP zeta potential was $-11 \mathrm{mV}$ in saline buffer at $\mathrm{pH} 7.4$ and, in the presence of chemotherapeutics, the MNP-GEM, MNP-PTX and MNP-GEM-PTX had their zeta potentials increased to $-4,-5$ and $-4 \mathrm{mV}$, respectively. Drug encapsulation did not change the MNPs size drastically, but the presence of GEM and PTX shifted the nanoparticle zeta potential close to zero, which could
A)

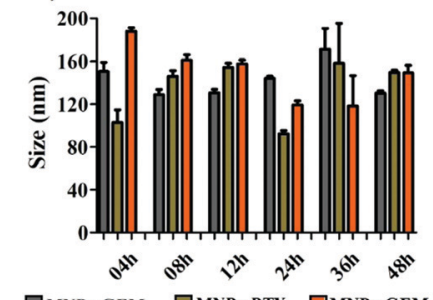

B)

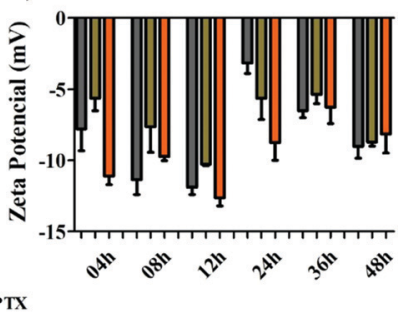

Fig. 1 Size (A) and zeta potential (B) of MNP-GEM, MNP-PTX and MNP-GEM-PTX at 4, 8, 16, 24, 36, and $48 \mathrm{~h}$ in DMEM supplemented with $10 \%$ FBS.

interfere with the nanoparticle stability. We analyzed MNPs superficial charge in lysosomes $\mathrm{pH}$ (4.4) and observed a negative zeta potential in the vesicles loaded with PTX. We also investigated nanoparticle stability in DMEM culture medium (Dulbecco's Modified Eagle's Medium) supplemented with fetal bovine serum (FBS). All groups of nanoparticles were incubated for 4 , $8,12,24,36$ and $48 \mathrm{~h}$ at $37{ }^{\circ} \mathrm{C}$ in a shaker before the analyses of size and zeta potential (Fig. 1).

Nanoparticle stability and aggregation phenomena are important parameters to be optimized for biological applications. As shown in Fig. 1, nanoparticles kept in cell culture medium maintained their hydrodynamic diameter despite the adsorption of proteins that created a protein corona on the MNPs surface. The interaction with FBS constituents reduced the MNP-GEMPTX zeta potential to $-13 \mathrm{mV}$, in contrast to the superficial charge in saline solution at $\mathrm{pH} 7.4(-4 \mathrm{mV})$. After $48 \mathrm{~h}$ of interaction with DMEM, we did not observe drastic variations in the size and superficial charge, demonstrating good stability in all experimental groups. Therefore, at physiological $\mathrm{pH}$, the nanoparticles with and without chemotherapeutics are stable in vitro during the period analyzed.

Atomic force microscopy (AFM) and field emission scanning electron microscopy (FEG-MEV) were used to investigate the morphology of the plasma membrane-derived nanoparticles from the pancreatic cancer cell line (Fig. S1, ESI $\dagger$ ). Transmission electron microscopy (TEM) images confirmed the results from DLS and NTA, with nanoparticle size around 100-400 nm. We also analyzed MNPs morphology and size distribution by cryomicroscopy (Cryo-TEM). Fig. 2 shows the nanoparticles containing PTX and GEM, which presented a vesicular shape. Additionally, we visualized a fuzzy shade in the lipid bilayer from MNP-GEM-PTX (Fig. 2D-F), indicating an interaction between chemotherapeutics

Table 1 Particle size and zeta potential based on NTA and DLS data

\begin{tabular}{|c|c|c|c|c|c|c|}
\hline \multirow[b]{3}{*}{ Nanoparticles } & \multicolumn{3}{|l|}{ pH 4.4} & \multicolumn{3}{|l|}{$\underline{\mathrm{pH}} 7.4$} \\
\hline & \multicolumn{2}{|l|}{$\underline{\text { Size }(\mathrm{nm})}$} & \multirow[b]{2}{*}{ Zeta potential $\zeta(\mathrm{mV})$} & \multicolumn{2}{|c|}{ Size $(\mathrm{nm})$} & \multirow[b]{2}{*}{ Zeta potential $\zeta(\mathrm{mV})$} \\
\hline & NTA & DLS & & NTA & DLS & \\
\hline MNPS & $238 \pm 4$ & $450 \pm 50$ & $4.33 \pm 1$ & $187 \pm 5$ & $242 \pm 2$ & $-11.23 \pm 1$ \\
\hline MNP-GEM & $155 \pm 5$ & $410 \pm 80$ & $1.54 \pm 1$ & $130 \pm 1$ & $142 \pm 2$ & $-4.26 \pm 2$ \\
\hline MNP-PTX & $226 \pm 7$ & $360 \pm 60$ & $-6.92 \pm 1$ & $122 \pm 2$ & $139 \pm 3$ & $-5.02 \pm 2$ \\
\hline MNP-GEM-PTX & $270 \pm 20$ & $250 \pm 60$ & $-8.61 \pm 1$ & $154 \pm 5$ & $152 \pm 4$ & $-4.15 \pm 1$ \\
\hline
\end{tabular}


and membrane proteins on the surface of the nanoparticles as verified by the change in the zeta potentials. The distinct dimensions of MNP-PTX and MNP-PTX-GEM are related to the drug retention and adsorption of culture medium proteins on the nanoparticle surface. As demonstrated by cryo-microscopy, the arrows indicate a shade created by protein corona constituents and chemotherapeutic molecules on the lipid bilayer. Protein-stabilizing

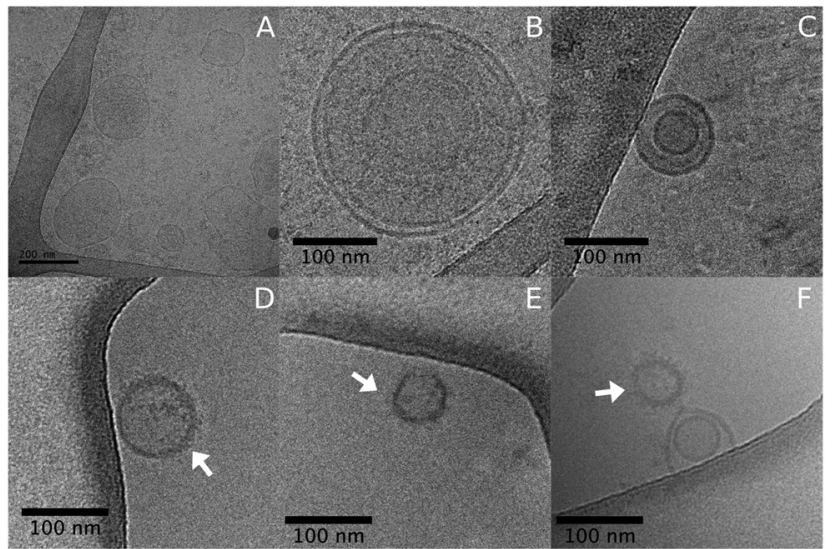

Fig. 2 Cryo-TEM images of plasma membrane nanoparticles (MNPs) extracted from the cancer cells (A and $B)$, after extrusion (C), and with MNP-GEM-PTX (D-F). The arrows indicate a shade created by the interaction of protein corona constituents and chemotherapeutic molecules on the lipid bilayer. molecules (PTX) or drugs to interfere in DNA replication (GEM) may affect the MNPs dimensions, folding the polypeptides by the chemotherapeutic agents' activities. A difference in the MNPs sizes was observed in the first $4 \mathrm{~h}$ after dispersion in DMEM as shown in Fig. 1. After $48 \mathrm{~h}$, these differences were no longer observed. In PBS at $\mathrm{pH}$ 7.4, the sizes of MNP-PTX and MNP-PTX-GEM were very close after the extrusion ( $\sim 139 \mathrm{~nm}$ and $\sim 152 \mathrm{~nm}$, respectively) (Table 1), revealing the effects from the culture medium proteins on the nanoparticle size stability during the in vitro experiments.

Incorporation of chemotherapeutic agents in MNPs was investigated by UV/Visible spectroscopy using the Beer-Lambert law for pure MNPs, MNP-GEM, and MNP-PTX (Fig. 3A). It was estimated that approximately $50 \mu \mathrm{M}$ of the drug was loaded in $1 \times 10^{9}$ particles, by measuring the absorbance value of MNPs and GEM at $262 \mathrm{~nm}$ and $270 \mathrm{~nm}$, respectively. Drug release was carried out in PBS ( $\mathrm{pH} 4.8$ and $\mathrm{pH} 7.4$ ) and the concentration was determined using GEM standard curves (Fig. 3B and C).

We estimated the protein concentration in the MNPs using Bradford's assay and gel electrophoresis. Approximately $150 \mu \mathrm{g} \mathrm{ml}^{-1}$ of 50-65 kDa-protein was extracted from $2 \times 10^{7}$ cells. We decided to confirm the MNPs composition by infrared spectroscopy, analyzing the chemical bonds present in polypeptide chains. Because of the high concentration of proteins, bands related to carbon, oxygen, and hydrogen are highlighted in the spectrum, verifying the effectiveness of chemical treatments in functionalized walls. The molecular vibrations of $\mathrm{O}-\mathrm{H}$ stretches, $\mathrm{N}-\mathrm{H}$ bonds and secondary amines were assigned in the graph
A)

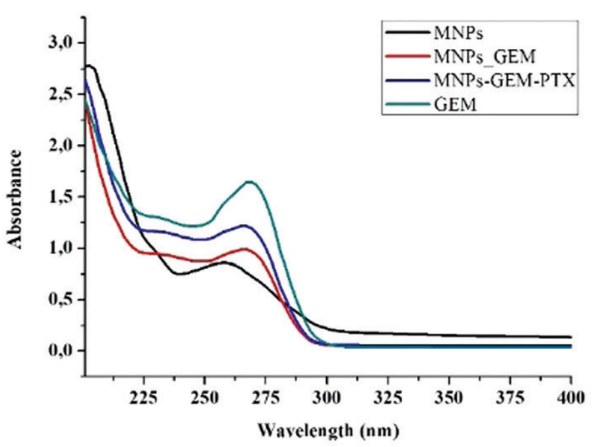

C)

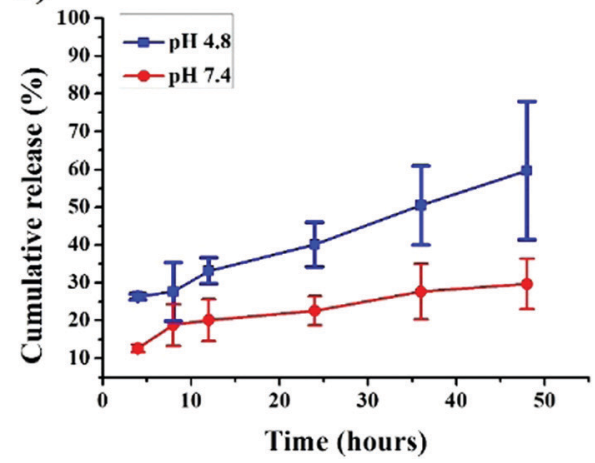

B)

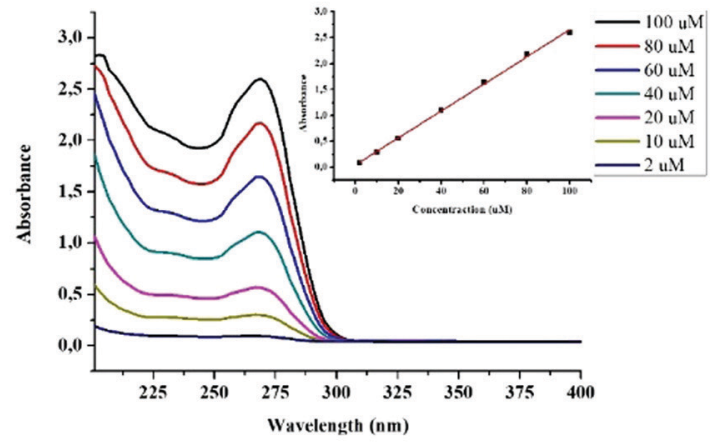

D)

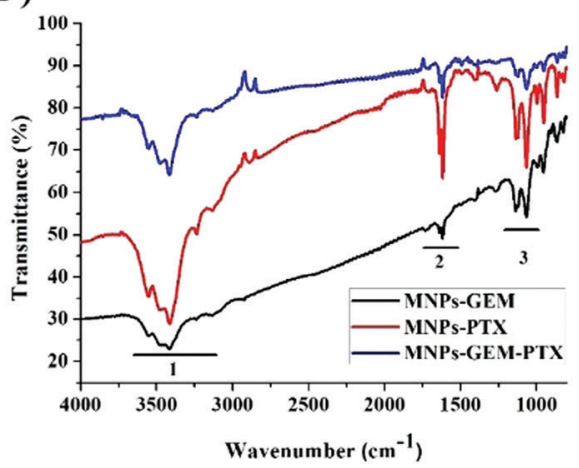

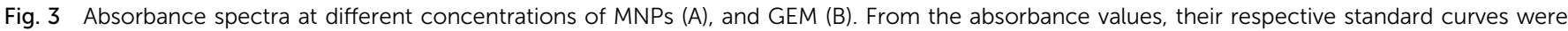

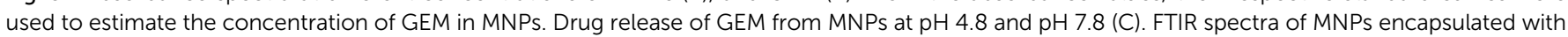
gemcitabine and paclitaxel (MNP-GEM, MNP-PTX, and MNP-GEM-PTX) (D). 
between $3200 \mathrm{~cm}^{-1}$ to $3700 \mathrm{~cm}^{-1}$ in all experimental groups (region 1, Fig. 3D). C-H, secondary amines, angular deformation of $\mathrm{N}-\mathrm{H}$ and $\mathrm{CH}_{2}-\mathrm{NH}_{2}$ bonds were observed in the region from $1500 \mathrm{~cm}^{-1}$ to $1750 \mathrm{~cm}^{-1}$ (region 2). The third region corresponds to carboxylic acid and $\mathrm{C}-\mathrm{N}$ stretching from primary amines (1100 $\mathrm{cm}^{-1}$ and $1200 \mathrm{~cm}^{-1}$, respectively).

\subsection{Interactions of nanoparticles with tumor cells and monocytes from healthy donors}

We used nanoparticles previously stained with fluorescein isothiocyanate (FITC) to investigate their interactions with pancreatic cancer cells, healthy liver cells, and immunocompetent cells.
FITC fluorochrome emits green light when excited with light at the wavelength of $488 \mathrm{~nm}$, and can be detected by flow cytometry. This assay was performed with only FITC-labeled MNPs to prove their interaction with tumor cells. As a result, we observed a high percentage of tumor cells FITC ${ }^{+}$, in contrast with the hepatic cell lines (Fig. 4A-D). The frequency of nanoparticles on the cell surface was estimated by examining the median fluorescence intensity (MFI). After treatment with MNPs, pancreatic cancer cells FITC $^{+}$doubled the value of MFI over their respective control groups (cells not exposed to MNPs). This result was not observed in HEPA-RG cell lines, indicating less interaction on the surface of hepatic cells and great specificity to PANC-1.
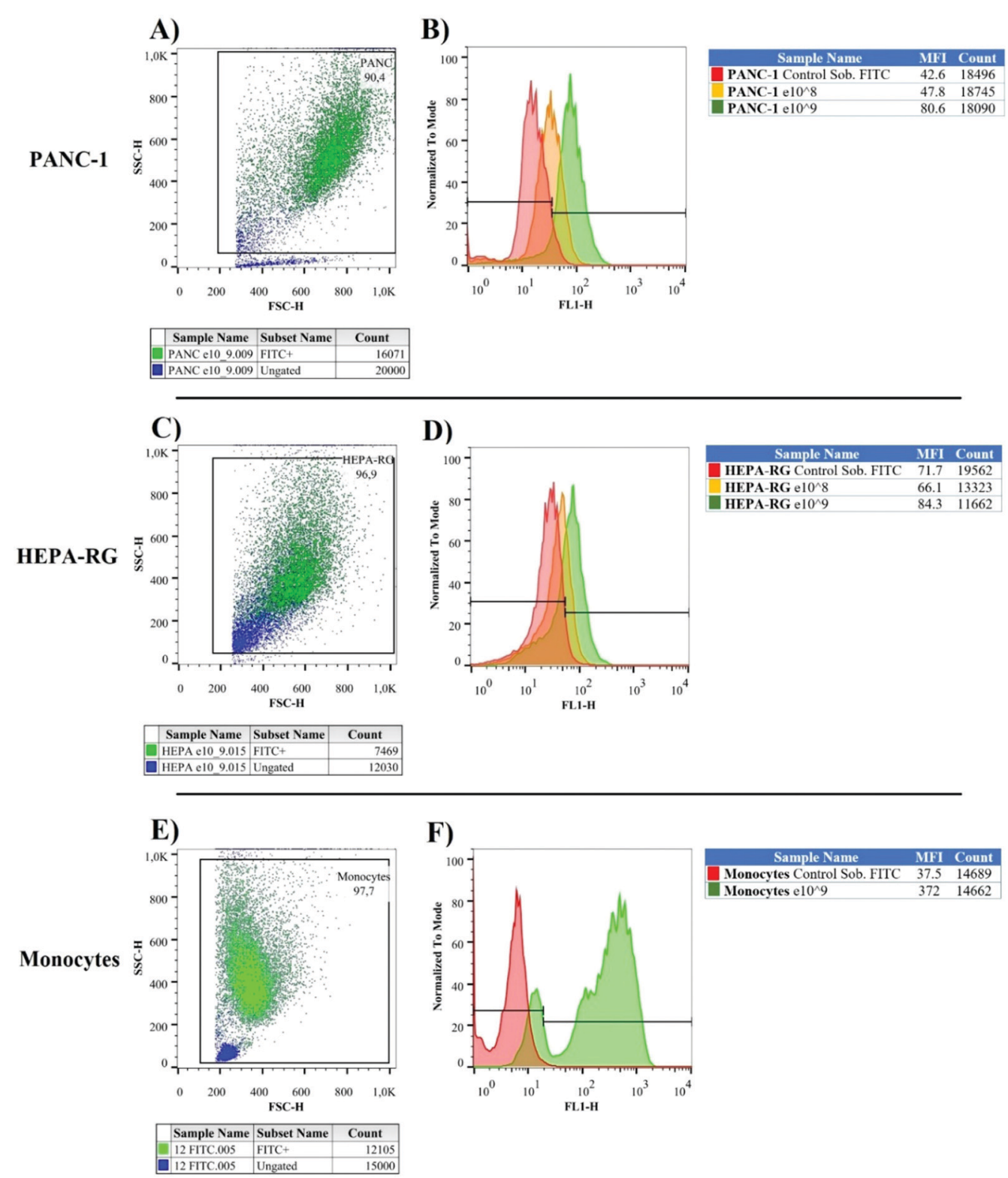

F)

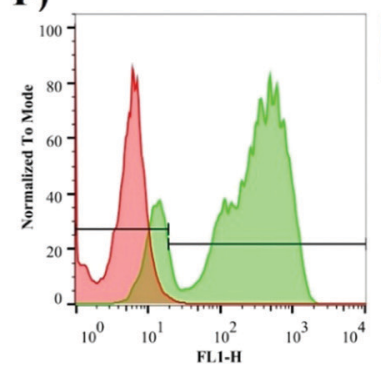

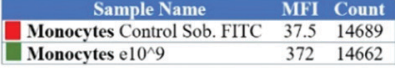

Monocytes e $10^{\wedge} 9$

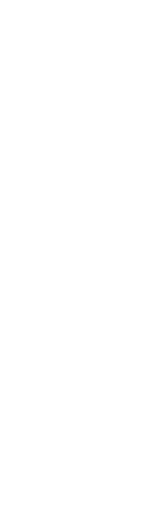


Monocytes, macrophages, neutrophils, and dendritic cells captured nanoparticle very quickly, limiting the delivery of chemotherapeutic agents in diseased sites. ${ }^{26,27}$ Consequently, we decided to investigate MNPs interactions with monocytes from healthy donors to confirm if peripheral blood cell phagocytes contained a large number of fluorescein-labeled particles (Fig. $4 \mathrm{E}$ and F). Our results indicate that $97 \%$ of monocytes were FITC $^{+}$with MFI values $10 \times$ greater than white blood cells treated with FITC stock solution in the same molar concentration adsorbed at MNPs (control group $=37.5 ; \mathrm{FITC}^{+}$-MNPs $=372$ ).

Confocal microscopy confirmed the specific internalization of MNPs in pancreatic cancer cells (Fig. S2, ESI $\dagger$ ). In PANC-1, red fluorescence from the cell membrane surrounded green fluorescence that did not interfere in blue fluorescence from the cell nucleus, suggesting the internalization of MNP-FITC ${ }^{+}$. The images revealed the nanoparticle distribution in the cytoplasm without membrane residue. Meanwhile, the presence of antigenic material improved the particle association on the pancreatic cell surface, making the intensity of MNPs more regular in the PANC-1 cytoplasm than in the control group with HEPA-RG cells (Fig. S2, ESI $\dagger$ ), as previously described by MFI values in Fig. $4 \mathrm{~B}$ and $\mathrm{D}$.

\subsection{Nanoparticle cytotoxicity}

We conducted the methyl tetrazolium (MTT) colorimetric assay to evaluate the toxicity of MNPs and chemotherapeutics in PANC-1 and HEPA-RG cell lines, determining their concentration for use in the in vitro experiments. Our data indicated that the exposure of pancreatic cancer to pure antineoplastic agents (Fig. 5A-C) did not promote the reduction in cell viability in all concentrations tested. These results were confirmed by apoptosis (annexin $\left.{ }^{+}\right)$ and necrosis $\left(7 \mathrm{AAD}^{+}\right)$assays performed in the flow cytometer (Fig. 5D-G). In contrast, pure GEM-PTX increased the treatment effectiveness in HEPA-RG (Fig. 5H-J), demonstrating the
A)

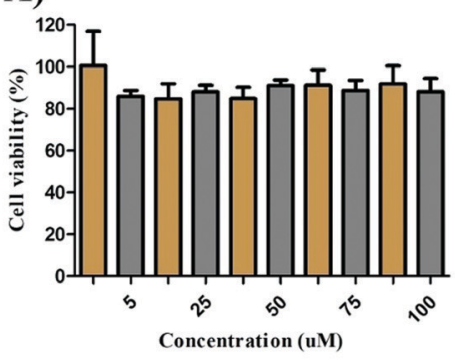

B)

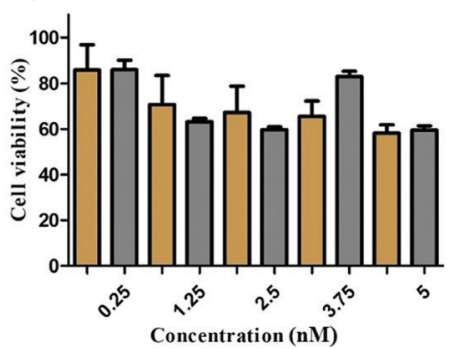

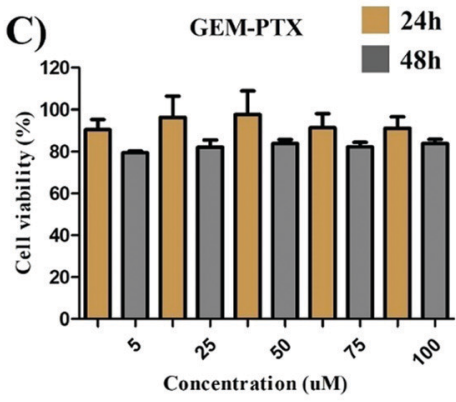

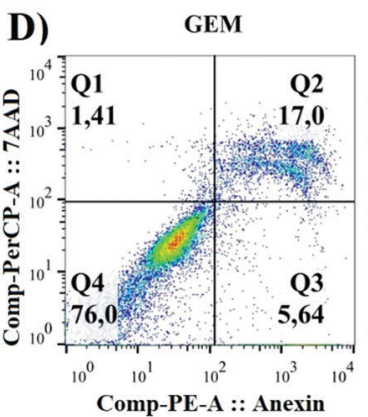

E)

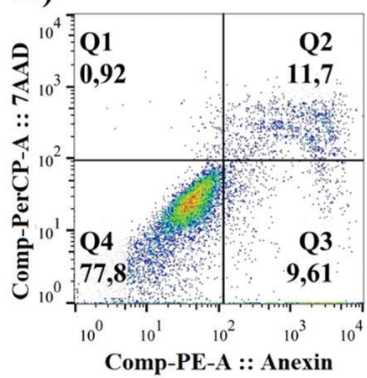

F)

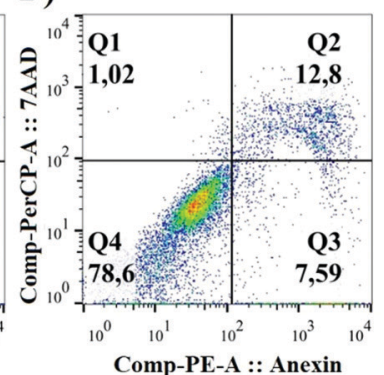

G)

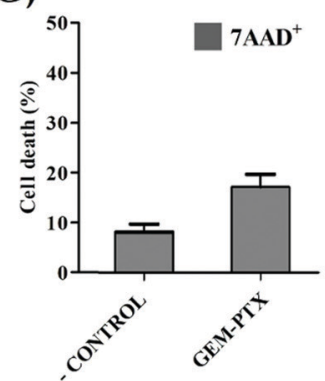

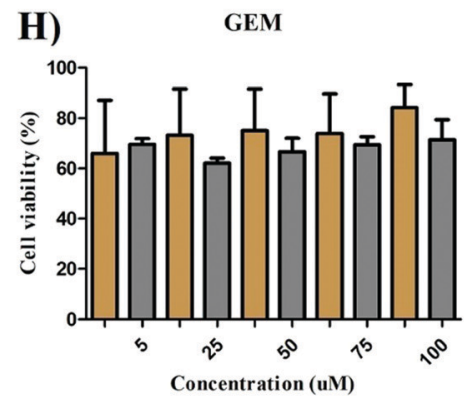

I)

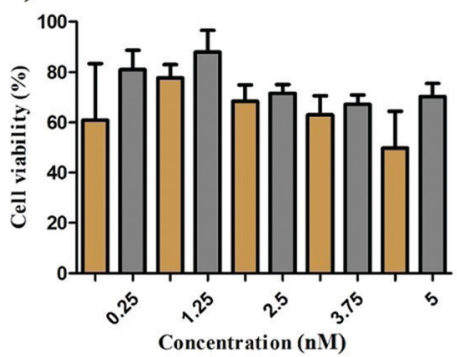

J)

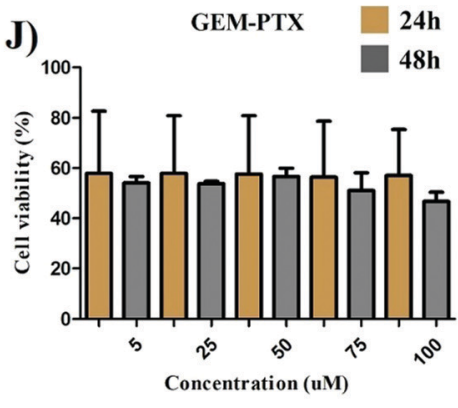

Fig. 5 Cytotoxicity analysis of GEM and PTX in pancreatic cancer cells (PANC-1) by methyl tetrazolium reduction (MTT). PANC-1 ( $1 \times 10^{4}$ cells per well) was exposed to five concentrations of pure GEM $(100 ; 75 ; 50 ; 25 ; 5 \mu \mathrm{M})(\mathrm{A})$, PTX alone $(5 ; 3.75 ; 2.5 ; 1.25$ and $0.25 \mathrm{nM})(\mathrm{B})$ and simultaneous exposure to both drugs (GEM-PTX) (C). We also analyzed cancer cell death by flow cytometry after treatment with GEM/PTX, labeling with annexin-V (FL2 channel), and 7AAD (FL3 channel). PANC-1 $\left(1 \times 10^{5}\right.$ cells per well) were exposed to $100 \mu \mathrm{M}$ of GEM (D), $5 \mathrm{nM}$ of PTX (E), and both GEM-PTX (F) to observe the cytotoxic response at the maximum drug concentration used in the MTT assay. Mean and SD of 3 independent assays (G). HEPA-RG $\left(1 \times 10^{4}\right.$ cells per well) were exposed to GEM $(100 ; 75 ; 50 ; 25 ; 5 \mu \mathrm{M})(\mathrm{H})$, PTX $(5 ; 3.75 ; 2.5 ; 1.25$ and $0.25 \mathrm{nM})(\mathrm{I})$, and GEM-PTX (J) to observe the chemotherapeutic activity in a healthy cell line. 
importance of using nanoparticles to inhibit side effects in untargeted cells.

Pure MNPs did not exhibit toxicity after $24 \mathrm{~h}$ and $48 \mathrm{~h}$ (Fig. S3a, ESI $\dagger$ ). Meanwhile, at $1 \times 10^{9}$ particles per ml, MNP-GEM reduced the tumor cell viability by $30 \%$ after $24 \mathrm{~h}$ of incubation with an increase in toxicity after $48 \mathrm{~h}$ (Fig. S3b, ESI $\dagger$ ).

For nanoparticles encapsulated with PTX, the cell viability was between $60 \%$ and $80 \%$ after $24 \mathrm{~h}$, and the low concentration of drugs allowed tumor cells to regrow after $48 \mathrm{~h}$ (Fig. S3c, ESI $\dagger$ ). The simultaneous delivery of two first-line chemotherapeutics (MNP-GEM-PTX) increased the nanoparticle toxicity, exhibiting greater efficacy at low concentrations in the period of $48 \mathrm{~h}$ (Fig. S3d, ESI $\dagger$ ). Consequently, we chose to work with $1 \times$ $10^{8}$ particles per $\mathrm{ml}$ in the subsequent tests with cancer cells and healthy peripheral blood cells.

Because the nanoparticles contained parts of pancreatic tumor cell membranes, we determined their specificity upon their incubation with healthy liver cell lines (HEPA-RG). The toxicity of MNP-GEM and MNP-PTX (Fig. S4b and c, ESI $\dagger$ ) was similar to PANC-1 after $48 \mathrm{~h}$ but MNP-GEM-PTX did not inhibit cell proliferation at low concentrations (Fig. S4d, ESI $\dagger$ ). In Fig. 6, we sum up the statistical relevance between PANC-1 and HEPA-RG after treatment with GEM+PTX and nanovesicles loaded with both molecules (MNP-GEM-PTX), demonstrating a higher activity of chemotherapeutics in neoplastic pancreatic cells than in hepatic cell lines when delivered by MNPs at the same molar concentration.

We observed the specificity and the superior cytotoxic effects produced by plasma-membrane-derived nanoparticles in contrast to synthetic lipid nanostructures (Fig. S5, ESI $\dagger$ ). Antineoplastic agents were also delivered into pancreatic cancer cells by liposomes synthesized with phosphatidylcholine, phosphatidylserine, and cholesterol (products obtained from Avanti ${ }^{\circledR}$ Polar Lipids). Synthetic liposomes loaded with Gemcitabine and/or Paclitaxel (Lipid-GEM, Lipid-PTX, and Lipid-GEM-PTX) were demonstrated to be less effective than MNPs groups (Fig. S5a-d, ESI $\dagger$ ). Interestingly, MNP-GEM-PTX exhibited superior activity in

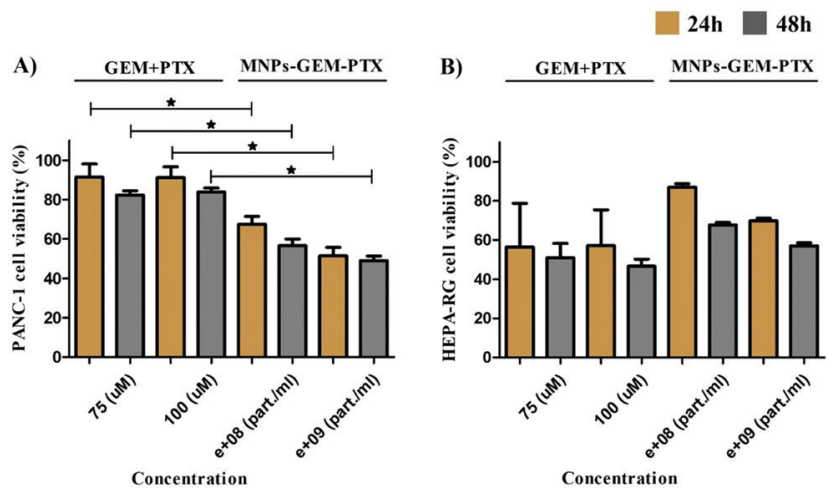

Fig. 6 Cytotoxicity analysis in pancreatic cancer cells (PANC-1) (A) and healthy liver cells (HEPA-RG) (B) by methyl tetrazolium reduction (MTT). PANC-1 and HEPA-RG $\left(1 \times 10^{4}\right.$ cells per well) were exposed to chemotherapeutic molecules (GEM+PTX) and MNPs encapsulated with both drugs (MNP-GEM-PTX) in the same molar concentration to verify their specificity and toxicity ( ${ }^{*} p \leq 0.05$ ). comparison to Lipid-GEM-PTX, indicating that the cell membrane components aid particle interaction in tumor cells.

\subsection{Cell death induced via apoptosis and/or necrosis}

Although MTT experiments indicated metabolic activity in the cells, we decided to verify cancer cell death using the Annexin-V/ 7AAD assay via flow cytometry. Aiming to investigate whether the MNP-GEM-PTX enhances the effectiveness against pancreatic cancer cells, the induction of apoptosis and/or necrosis cell death was analyzed by labeling Annexin-V and 7-AAD. Annexin-V binds to phosphatidylserine on the cellular membrane. Cells undergoing apoptosis expose this phospholipid on the external surface, enabling the binding of annexin. Moreover, osmotic lysis creates pores on the plasma membrane, allowing 7-AAD to infiltrate and label necrotic cells. After exposure to MNP-GEM-PTX, PANC-1 cells undergo a higher cell death $\left(7 \mathrm{AAD}^{+}=26\right.$; Annexin $\left.\mathrm{V}^{+}=27 \%\right)$ (Fig. 7A) than HEPA-RG $\left(7 \mathrm{AAD}^{+}=6 \%\right.$; Annexin $\left.\mathrm{V}^{+}=8 \%\right)$ (Fig. 7B). The combination of PTX and GEM in a single nanoparticle (MNPGEM-PTX) increased the cytotoxic effects in neoplastic cells in comparison to MNP-GEM and GEM alone, indicating that the microtubule-stabilizing agent favors gemcitabine activity as revealed by previous studies in clinical trials with pure anti-neoplastic drugs. ${ }^{28}$

\subsection{MNPs effects on monocyte and DCs phenotype from healthy donors}

Since monocytes intensely phagocytose MNPs, we examined whether such events would affect cell phenotype and immune responses. Human monocytes and dendritic cells (DCs) were exposed to nanoparticles and the expression of surface markers necessary for antigen-presenting activity was evaluated. Nanoparticles synthesized with GEM and PTX (MNP-GEM-PTX) increased HLA-DR expression while other treatments did not exhibit an equal response (Fig. 8A, B and 9A, B). We also observed that MNPs activated co-stimulatory markers, such as CD80, CD83, CD86, and PD-L1 (Fig. 8C-J and 9C-J), whereas pure GEM-PTX treatment did not exhibit the same effect. The exposure to MNPs promoted an intense phenotype change in APCs, indicating that nanoparticles interfered in immune cell activation, as confirmed by HLA-DR ${ }^{+}, \mathrm{CD}^{+} 0^{+}, \mathrm{CD}^{\circ} 3^{+}$, and $\mathrm{CD}^{+} 6^{+}$expression.

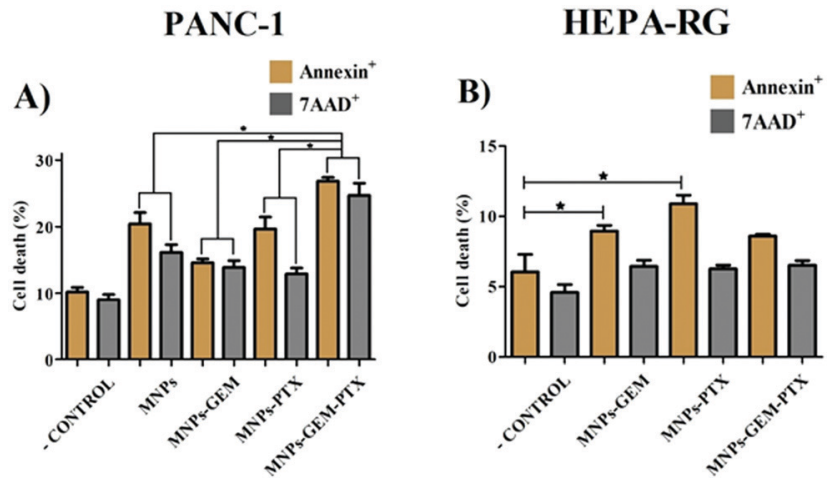

Fig. 7 The effects of plasma membrane-derived nanoparticles on the viability of tumor (PANC-1) (A) and healthy cells (HEPA-RG) (B) (Annexin $\mathrm{V}^{+}$ and $7 A A D^{+}$) after $48 \mathrm{~h}$ of exposure to MNPs, MNP-GEM, MNP-PTX, MNPGEM-PTX $\left({ }^{*} p \leq 0.05\right)$. 
Monocytes

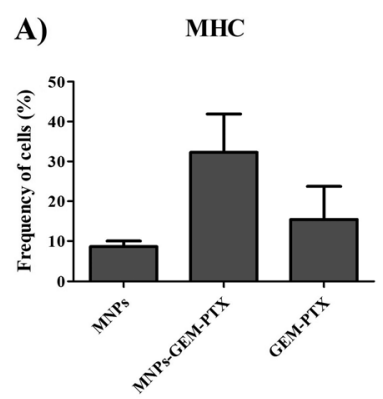

C)

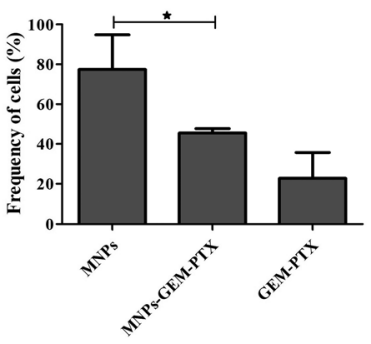

E)

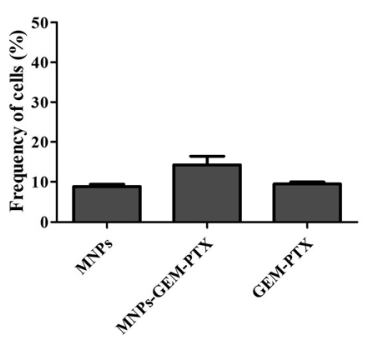

G)

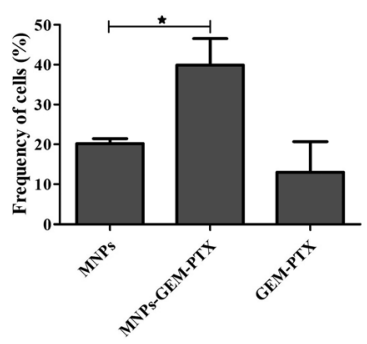

I)

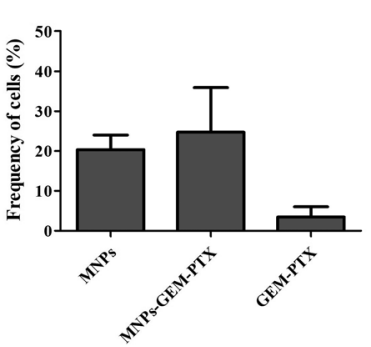

B)
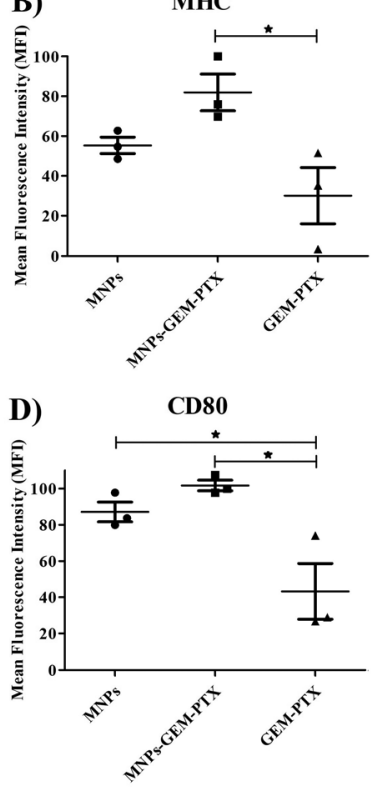

F) $\quad \mathrm{CD83}$

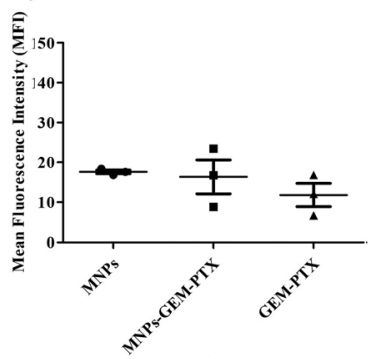

H) $\quad \mathrm{CD86}$
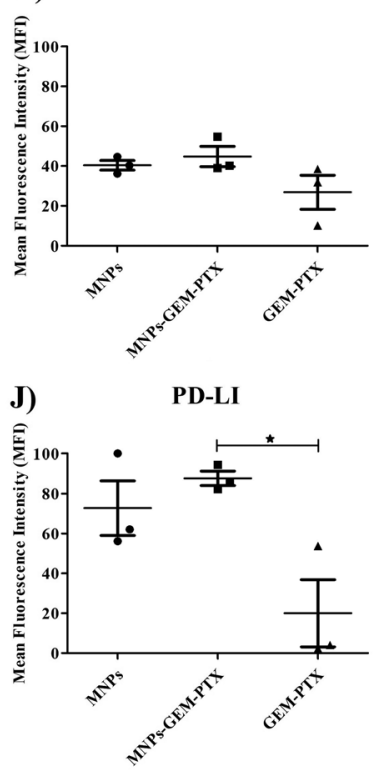

Fig. 8 Molecule expression on monocytes after different treatments. We observed the percentage of cells expressing HLA-DR $(A$ and $B), C D 80^{+}(C$ and $D), C D_{83} 3^{+}(E$ and $F), C D 86^{+}(G$ and $H)$ and PD-L1+ (I and J). The treatment groups were composed of MNPs, MNP-GEM-PTX and GEMPTX $\left({ }^{*} p \leq 0.05\right)$.

Dendritic cells
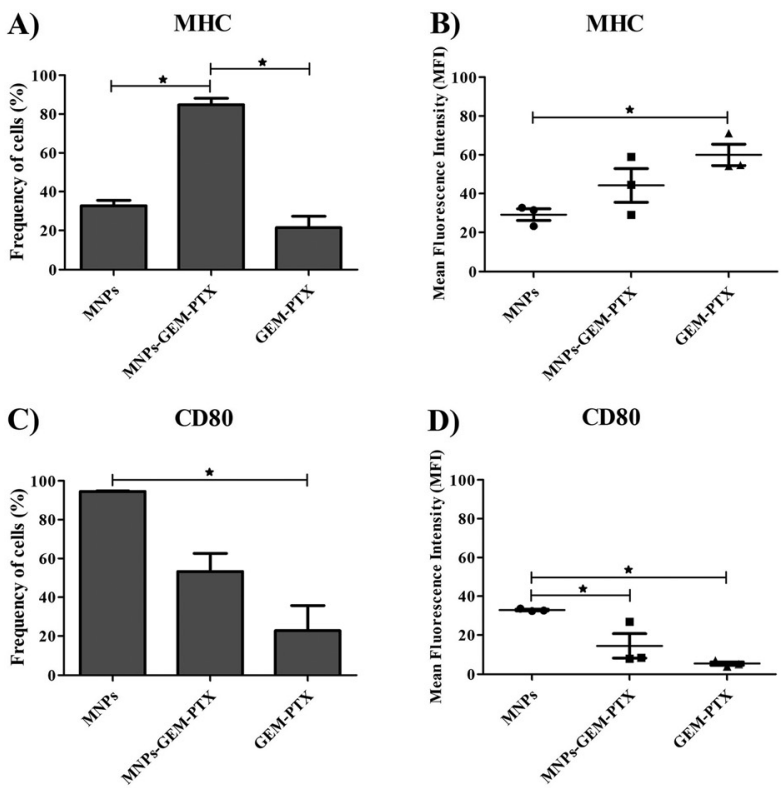

D) CD80

E)

CD83
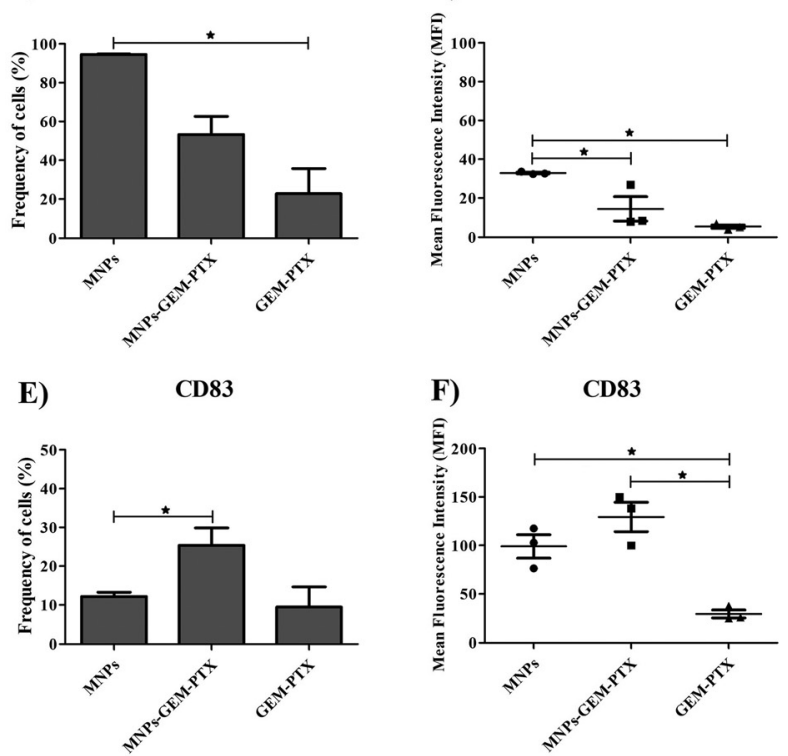

F) $\quad$ CD83

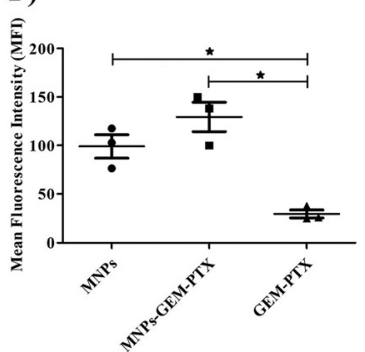

G)

CD86
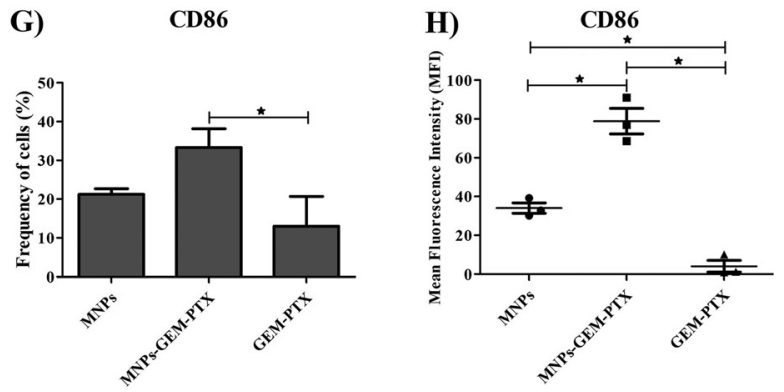

I)

PD-LI
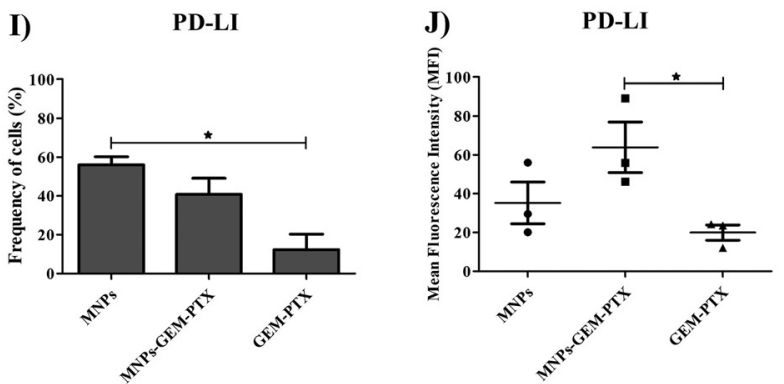

Fig. 9 Expression of molecules on dendritic cells after different treatments with MNPs. We observed the percentage of cells expressing $\mathrm{HLA}-\mathrm{DR}^{+}(\mathrm{A}$ and $\mathrm{B})$, $\mathrm{CD}^{+} 0^{+}(\mathrm{C}$ and $\mathrm{D}), \mathrm{CD}^{+} 3^{+}(\mathrm{E}$ and $\mathrm{F}), \mathrm{CD}^{+} 6^{+}\left(\mathrm{G}\right.$ and H) and PD-L1 ${ }^{+}(\mathrm{I}$ and $\mathrm{J})$. The treatment groups were composed of MNPs, MNP-GEM-PTX and GEM-PTX. The results were normalized by $\mathrm{Control}^{+}$(representing DCs that were treated with activation cocktail to differentiate into mature $\mathrm{DC}-\mathrm{mDCs}$ ) and the $\mathrm{Control}^{-}$ (representing DCs that did not receive treatments) $\left({ }^{\star} p \leq 0.05\right)$. 


\subsection{Mixed lymphocyte reaction (MLR) assays}

The main function of DCs is to present antigenic material to $\mathrm{T}$ lymphocytes. DCs capture foreign antigens, process and express the fragments (epitopes) associated with major histocompatibility complex (MHC) to be recognized by T cells. Since lymphocytes are stimulated to proliferate after binding the alloantigen molecules on DCs, they are co-cultivated in Mixed Lymphocyte Reaction (MLR) assays to reproduce immune cell interactions between MHC and T-cell receptors in vitro. Here, DCs were previously treated with MNPs for $48 \mathrm{~h}$ and co-cultured with allogeneic lymphocytes (from different individuals) at the end of this period. After 5 days, we analyzed the total $\mathrm{T}$ cell proliferation $\left(\mathrm{CD}^{+}, \mathrm{CD}^{+}\right.$, and $\left.\mathrm{CD}^{+}\right)$, as shown in Fig. 10B, indicating a reduction in DCs ability to induce an allogenic response after exposure to MNP-GEM-PTX, as well as GEM-PTX alone. Although we observed an inefficient allogeneic response from DCs after incubation with nanoparticles carrying chemotherapeutics, MNPs alone increased lymphocyte interaction with pancreatic cancer cell surfaces (Fig. 10C and E). The proteins present in nanovesicles may be processed in DCs and show the antigenic material to total T cells, allowing lymphocytes to recognize pancreatic cell lines. These results were not reproducible in immature DCs (iDCs), immune cells not exposed to antigenic material present in nanovesicles and any other experimental treatments (Fig. 10D and F).

\section{Discussion}

We investigated plasma membrane-derived lipid nanoparticles to transport gemcitabine and paclitaxel, testing their effectiveness on pancreatic cancer cells and also their effects on immunocompetent cells. The toxicity of the experimental groups was evaluated in tumor cells and their immunoregulatory properties in human lymphocytes, monocytes and dendritic cells (DCs) generated in vitro from healthy donors. We synthesized nanovesicles from the main components of neoplastic cell membranes to deliver two first-line chemotherapeutics since the high expression of adhesion molecules favor their association in cancer receptors. Macromolecule residues, e.g., from proteins, contribute to the increased nanoparticle dispersivity in aqueous suspensions, aiding in the avoidance of particle agglomeration and facilitating the encapsulation of additional substances. ${ }^{29}$

To incorporate larger amounts of antineoplastic agents in the nanoparticles, we extruded the real membranes with chemotherapeutic molecules through a polycarbonate membrane of $100 \mathrm{~nm} .{ }^{29}$ After extrusion, physicochemical characterizations were performed to analyze the differences in the nanocarrier structure before and after the incorporation of different agents. Initially, we verified the presence of protein radicals on MNPs by FTIR. Specifically, we observed the bands at 1150, 1625, and $3400 \mathrm{~cm}^{-1}$ corresponding to $\mathrm{C}-\mathrm{N}, \mathrm{CH}_{2}-\mathrm{NH}_{2}$, and $\mathrm{CH}_{2}-\mathrm{NH}-\mathrm{CH}_{2}$ groups presented in the primary and secondary amines from amino acids. ${ }^{30}$ The same pattern was also observed in experimental groups encapsulated with GEM and PTX. AFM, SEM and TEM microscopy revealed that no structural changes occurred in the nanoparticles spherical format after the encapsulation of the chemotherapeutics, which exhibited sizes between $100 \mathrm{~nm}$ and $250 \mathrm{~nm}$. Additionally, cryo-TEM analysis (Fig. 2) showed a fuzzy smudge in the lipid bilayer of the MNPS-GEM-PTX,
A)

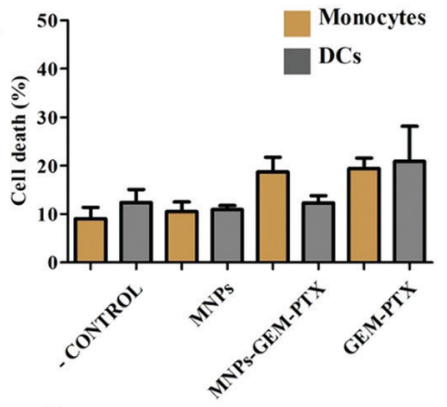

B)

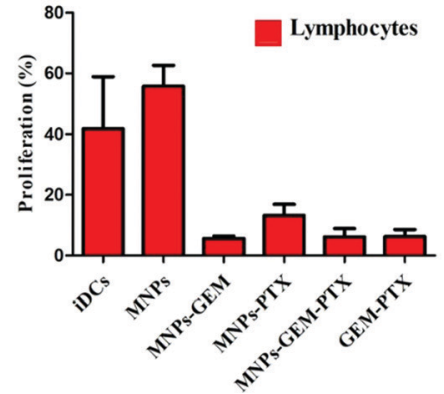

C)

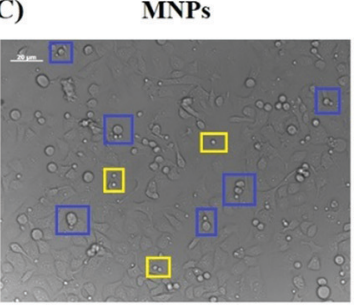

E)

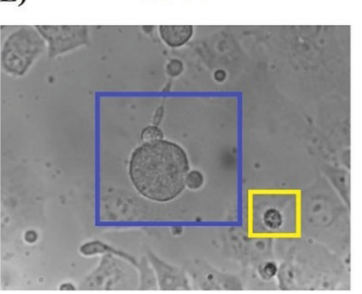

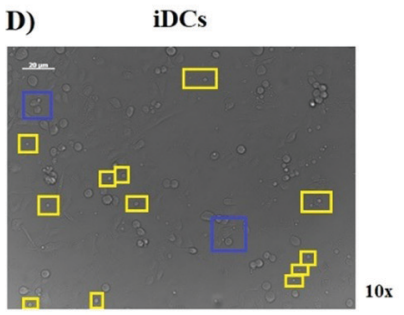

F)

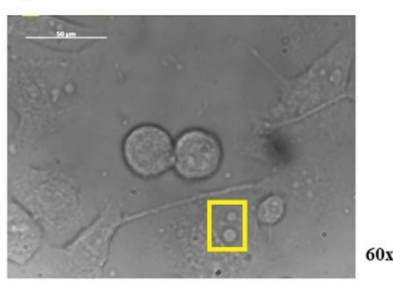

Fig. 10 Cytotoxicity of nanoparticles in human monocytes and DCs are illustrated by 7AAD ${ }^{+}$(A) labeling after exposure to MNPs, MNP-GEM-PTX, and GEM-PTX treatments. Total lymphocytes were co-cultured for 5 days with DCs to verify lymphoid cell proliferation. Analysis was performed after incubating total T cells with MTT salt, revealing the rate of proliferation after exposure to DCs previously treated with MNPS, MNP-GEM, MNP-PTX, MNPS-GEM-PTX, and GEM-PTX only (B). Optical microscopy images $(10 \times$ and $60 \times$ magnification) exhibit the contact between total T cells on the pancreatic cell surface. Blue squares show lymphocytes adsorbed on tumor cell membranes and the yellow squares indicate the lymphocytes at the bottom of the culture well plate ( $C$ and $E)$. The same rate of interaction was not observed using lymphocytes co-cultured with the negative control group (DCs that did not receive any treatment), increasing the number of isolated lymphocytes (yellow squares) (D and F). 
which indicated the interaction of the antineoplastic agents with the outer surface of lipid nanoparticles. ${ }^{31}$ The overshadows in the images of MNPs were intensified due to interactions with proteins, fragments of DNA, and RNA left by this method of isolation..$^{32}$ The presence of drug molecules on the MNPs surfaces was confirmed by the zeta potential values close to zero in MNPGEM, MNP-PTX, and MNP-GEM-PTX groups at pH 7.4.

After labeling the MNPs with FITC, we analyzed the interactions between nanoparticles and tumor cell cultures and human monocytes by flow cytometry and confocal microscopy (Fig. 4 and Fig. S2, respectively, ESI + ). MNP-FITC ${ }^{+}$revealed the interactions between nanoparticles and PANC-1 tumor cells, HEPARG cells and primary monocytes from healthy donors, observing a high median fluorescence intensity (MFI) in pancreatic cells FITC $^{+}$(whose plasma membranes were extracted to synthesize the nanocomposite) and white blood cells.

Encapsulation efficiency was 50\% for GEM, with a cumulative release of $25 \%$ in $48 \mathrm{~h}\left(10^{9}\right.$ particle per $\left.\mathrm{ml}\right)$ at $\mathrm{pH}$ 7.4. Our data indicated that PANC-1 exposure to pure antineoplastic agents $(\mathrm{GEM}=100 \mu \mathrm{M}$ and PTX $=5 \mathrm{nM})$ did not reduce cell viability at the same molar concentration used in nanoparticle synthesis $(5 \mathrm{~A}$ to $5 \mathrm{~F}$ ). Previous results indicated a half-maximal inhibitory concentration $\left(\mathrm{IC}_{50}\right)$ of GEM and PTX above $100 \mu \mathrm{M}$ and $10 \mathrm{nM}$, respectively. ${ }^{33,34}$ A low concentration of nanoparticle $(1 \times$ $10^{8}$ particle per $\mathrm{ml}$ ) was chosen here to check the improvement produced by MNPs in the treatments. As observed in Fig. 6, pure chemotherapeutics were toxic to HEPA-RG and nanoparticles reduced drug activity in this healthy cell line. Additionally, the liposome nanocarriers showed the same behavior as the free agents when interacting with PANC-1, proving the importance of the plasma membrane proteins for delivery.

The apoptosis/necrosis assay confirmed the low toxicity of MNPs in PANC-1 and HEPA-RG cells (Fig. 7). However, we observed similar toxicity between nanoparticles encapsulated with only one chemotherapeutic agent, indicating the low therapeutic efficiency of the drugs when carried individually in pancreatic cancer cells. PTX incorporation (MNP-GEM-PTX) increased the nanoparticle toxicity, increasing cell death, which leads us to conclude that the presence of PTX improved the cytotoxic capacity of MNP-GEM. Therefore, our results suggest that MNP-GEM-PTX could be more effective than pure GEM and pure PTX in a short period of treatment. This finding is similar to previous studies with nanoparticles conjugated with GEM plus the administration of pure PTX, exhibiting greater toxicity than the simple treatment with GEM on lung, ${ }^{35}$ mammary, and ovary cancer cells. ${ }^{36,37}$

The most interesting result was observed in the MNPGEM-PTX group, indicating that paclitaxel favors MNP-GEM activity in tumor cells (Fig. 7A and Fig. S3, ESI $†$ ). Our purpose to deliver antineoplastic agents inside neoplastic cells using plasma membrane-derived nanoparticle was successfully achieved since MNP-GEM-PTX induced more apoptosis/necrosis in PANC-1 than in HEPA-RG. However, it was not sufficient to prevent nanoparticle interaction with monocytes, with MNPs changing their phenotype (Fig. S6 and S7, ESI $\dagger$ ) and immune function.

Phagocytic cell engulfment can be used to improve nanocarrier efficiency. In monocytes, MNP-GEM-PTX increased HLA-DR protein and costimulatory molecules CD80, CD83, and CD86 expression, as shown in Fig. 8A-H. This is a relevant result because the nanocomposites can help to re-educate immune-suppressed cells, activating their cytotoxic response in the tumor microenvironment and secondary lymphoid organs. In monocytes, MFI values indicated an increase in HLA-DR expression after exposure to nanoparticles, which did not occur for nonencapsulated PTX-GEM (Fig. 8B). The high expression of HLADR is not unexpected since previous studies reported that low doses of GEM and PTX increased the frequency of this activation marker in dendritic cells, increasing immune-cell ability to elicit an anti-tumor response in vitro. ${ }^{38,39}$ Furthermore, chemotherapeutics delivered by MNPs increased the expression of CD80 and CD86 molecules on the cells. Both molecules are essential in the process of antigen presentation by macrophages and dendritic cells to present antigenic peptides to $\mathrm{CD}^{+}{ }^{+} \mathrm{T}$ cells. ${ }^{40}$ The expression of $\mathrm{CD} 83$ (maturation marker protein) was also analyzed and remained constant in monocytes and increased in DCs surface (Fig. 8E, $\mathrm{F}$ and $9 \mathrm{E}, \mathrm{F}$ ). Taxol interferes in the assembly and disassembly of microtubules during cell division; ${ }^{41}$ treatment with MNP-GEMPTX increases HLA-DR expression on dendritic cells due to the effect on antigen processing and presentation via MHC on the cell surface. Similar to the histocompatibility complex, DCs also increase the frequency of CD83 and CD86 after treatment with MNP-GEM-PTX, suggesting that the expression of costimulatory molecules may be dependent on antigen processing.

Since nanoparticles induce low cytotoxicity in monocytes (Fig. 10A), we evaluated the DCs' antigen presentation capability induced by MNP-GEM-PTX, observing their influence on DCs in mixed lymphocyte reactions (MLR) (Fig. 10B). Our results demonstrated a high expression of maturation markers, HLA-DR, CD80, CD86, and CD83 after $48 \mathrm{~h}$. This did not inhibit the suppressive effects of chemotherapeutic molecules carried by cancer cell membrane-derived nanoparticles in DCs. The MNPs combined with chemotherapeutics could not prevent lymphocytopenia in future patient treatments, which could be explained by the fact that the agents are interacting in the outer membrane, decreasing the zeta potential values and releasing free working drugs. The depression of allogeneic stimulation may be a consequence of the GEM-PTX cytotoxicity. Since the concentrations examined in this study interfered with lymphocyte proliferation, we reinforce the importance of observing nanoparticle activity in the host immune surveillance cells to achieve a safe antitumor response and to avoid the risk of inducing tolerance.

The antigenic material carried in MNPs seems to promote low allogeneic stimulation. When we examined the activity of lymphocytes co-cultured with DCs treated with MNPs (without chemotherapeutic agents), recognition of total $\mathrm{T}$ cells with pancreatic cancer cells was observed (Fig. 10C and E) as a result of the delivery of cell membrane proteins. The same was not observed for DCs without any treatment (iDCs) (Fig. 10D and F).

In summary, we have developed a novel nanostructure for enhancing cancer immunogenicity and modulating the activity of antigen-presenting cells. We synthesized nanoparticles with the main components of pancreatic cancer cell membranes to deliver chemotherapeutics in diseased cells and to transport 
immunomodulatory agents to carcinoma and immunocompetent cells. Our studies revealed that MNPs are efficient carriers of chemotherapeutics for pancreatic cancer cells, producing cytotoxic effects superior to pure chemotherapy. Although highly phagocyted by monocytes, MNPs did not reveal immune toxicity, inducing the expression of HLA-DR, CD80, CD83, and CD86. Our results contribute to understanding the application of MNPs as antineoplastic agents nanocarriers and their effects on pancreatic cancer and immunocompetent cells. Therefore, this study aids nanomedicine and immunotherapy in complementing each other, encompassing their knowledge to create new therapies to reduce the adverse effects of treatments and to increase clinical results in the future.

\section{Conflicts of interest}

The authors declare no competing financial interest.

\section{Acknowledgements}

This study was funded by the São Paulo Research Foundation (FAPESP) (project number 2018/12670-4) and Brazilian National Council for Scientific and Technological Development (CNPq) (project number 142285/2017-0). The authors acknowledge the Brazilian Nanotechnology National Laboratory (LNNano) for the free use of their facilities (TEM-25144).

\section{References}

1 G. A. Roth, D. Abate, K. H. Abate, S. M. Abay, C. Abbafati, N. Abbasi, H. Abbastabar, F. Abd-Allah, J. Abdela and A. Abdelalim, Lancet, 2018, 392, 1736-1788.

2 F. Bray, J. Ferlay, I. Soerjomataram, R. L. Siegel, L. A. Torre and A. Jemal, Ca-Cancer J. Clin., 2018, 68, 394-424.

3 A. McGuigan, P. Kelly, R. C. Turkington, C. Jones, H. G. Coleman and R. S. McCain, World J. Gastroenterol., 2018, 24, 4846-4861.

4 G. Feldmann, R. Beaty, R. H. Hruban and A. Maitra, Journal of hepato-biliary-pancreatic surgery, 2007, 14, 224-232.

5 M. Abotaleb, P. Kubatka, M. Caprnda, E. Varghese, B. Zolakova, P. Zubor, R. Opatrilova, P. Kruzliak, P. Stefanicka and D. Büsselberg, Biomed. Pharmacother., 2018, 101, 458-477.

6 C. Fiorini, M. Cordani, C. Padroni, G. Blandino, S. Di Agostino and M. Donadelli, Biochim. Biophys. Acta, 2015, 1853, 89-100.

7 C. Springfeld, D. Jager, M. W. Buchler, O. Strobel, T. Hackert, D. H. Palmer and J. P. Neoptolemos, Presse Med., 2019, 48, e159-e174.

8 D. D. Von Hoff, T. Ervin, F. P. Arena, E. G. Chiorean, J. Infante, M. Moore, T. Seay, S. A. Tjulandin, W. W. Ma, M. N. Saleh, M. Harris, M. Reni, S. Dowden, D. Laheru, N. Bahary, R. K. Ramanathan, J. Tabernero, M. Hidalgo, D. Goldstein, E. Van Cutsem, X. Wei, J. Iglesias and M. F. Renschler, N. Engl. J. Med., 2013, 369, 1691-1703.

9 D. J. Lundy, K. H. Chen, E. K. Toh and P. C. Hsieh, Sci. Rep., 2016, 6, 25613.
10 D. Peer, J. M. Karp, S. Hong, O. C. Farokhzad, R. Margalit and R. Langer, Nat. Nanotechnol., 2007, 2, 751.

11 R. W. Robey, P. R. Massey, L. Amiri-Kordestani and S. E. Bates, Anti-Cancer Agents Med. Chem., 2010, 10, 625-633.

12 H. Sun, J. Su, Q. Meng, Q. Yin, L. Chen, W. Gu, P. Zhang, Z. Zhang, H. Yu, S. Wang and Y. Li, Adv. Mater., 2016, 28, 9581-9588.

13 Z. Chen, P. Zhao, Z. Luo, M. Zheng, H. Tian, P. Gong, G. Gao, H. Pan, L. Liu, A. Ma, H. Cui, Y. Ma and L. Cai, ACS Nano, 2016, 10, 10049-10057.

14 A. V. Kroll, R. H. Fang and L. Zhang, Bioconjugate Chem., 2017, 28, 23-32.

15 A. V. Kroll, R. H. Fang, Y. Jiang, J. Zhou, X. Wei, C. L. Yu, J. Gao, B. T. Luk, D. Dehaini, W. Gao and L. Zhang, Adv. Mater., 2017, 29, 1703969.

16 S. T. Yurkin and Z. Wang, Nanomedicine, 2017, 12, 2007-2019.

17 J. J. Moon, H. Suh, A. Bershteyn, M. T. Stephan, H. Liu, B. Huang, M. Sohail, S. Luo, S. H. Um and H. Khant, Nat. Mater., 2011, 10, 243-251.

18 M. Finkelstein and G. Weissmann, J. Lipid Res., 1978, 19, 289-303.

19 T. Kataoka and J. R. W. S. Kinsky, Biochim. Biophys. Acta, Biomembr., 1973, 298, 158-179.

20 M. Baghdadi, H. Wada, S. Nakanishi, H. Abe, N. Han, W. E. Putra, D. Endo, H. Watari, N. Sakuragi, Y. Hida, K. Kaga, Y. Miyagi, T. Yokose, A. Takano, Y. Daigo and K. I. Seino, Cancer Res., 2016, 76, 6030-6042.

21 X. Luan, Y.-Y. Guan, J. F. Lovell, M. Zhao, Q. Lu, Y.-R. Liu, H.-J. Liu, Y.-G. Gao, X. Dong and S.-C. Yang, Biomaterials, 2016, 95, 60-73.

22 Z. Amoozgar, L. Wang, T. Brandstoetter, S. S. Wallis, E. M. Wilson and M. S. Goldberg, Biomacromolecules, 2014, 15, 4187-4194.

23 W. Tang, J. Yang, Y. Yuan, Z. Zhao, Z. Lian and G. Liang, Nanoscale, 2017, 9, 6529-6536.

24 R. Lund, R. Leth-Larsen, O. N. Jensen and H. J. Ditzel, J. Proteome Res., 2009, 8, 3078-3090.

25 S. Winzen, S. Schoettler, G. Baier, C. Rosenauer, V. Mailaender, K. Landfester and K. Mohr, Nanoscale, 2015, 7, 2992-3001.

26 R. Weissleder, M. Nahrendorf and M. J. Pittet, Nat. Mater., 2014, 13, 125-138.

27 P. Korangath, J. D. Barnett, A. Sharma, E. T. Henderson, J. Stewart, S.-H. Yu, S. K. Kandala, C.-T. Yang, J. S. Caserto, M. Hedayati, T. D. Armstrong, E. Jaffee, C. Gruettner, X. C. Zhou, W. Fu, C. Hu, S. Sukumar, B. W. Simons and R. Ivkov, Sci. $A d v ., 2020,6$, eaay1601.

28 D. D. Von Hoff, T. Ervin, F. P. Arena, E. G. Chiorean, J. Infante, M. Moore, T. Seay, S. A. Tjulandin, W. W. Ma and M. N. Saleh, N. Engl. J. Med., 2013, 369, 1691-1703.

29 R. H. Fang, C. M. Hu, B. T. Luk, W. Gao, J. A. Copp, Y. Tai, D. E. O'Connor and L. Zhang, Nano Lett., 2014, 14, 2181-2188.

30 T. E. Madey and J. T. Yates Jr, Vibrational Spectroscopy of Molecules on Surfaces, Springer Science \& Business Media, 2013.

31 C. Corbo, R. Molinaro, F. Taraballi, N. E. T. Furman, M. B. Sherman, A. Parodi, F. Salvatore and E. Tasciotti, Int. J. Nanomed., 2016, 11, 3049. 
32 J. M. Suski, M. Lebiedzinska, A. Wojtala, J. Duszynski, C. Giorgi, P. Pinton and M. R. Wieckowski, Nat. Protoc., 2014, 9, 312.

33 R. A. Fryer, B. Barlett, C. Galustian and A. G. Dalgleish, Anticancer Res., 2011, 31, 3747-3756.

34 Y. Lin, F. Richards, B. Krippendorff, J. Bramhall, J. Harrington, T. Bapiro, A. Robertson, D. Zheleva and D. Jodrell, Br. J. Cancer, 2012, 107, 1692-1701.

35 R. Zhang, J. Yang, M. Sima, Y. Zhou and J. Kopeček, Proc. Natl. Acad. Sci. U. S. A., 2014, 111, 12181-12186.

36 M. Lei, S. Sha, X. Wang, J. Wang, X. Du, H. Miao, H. Zhou, E. Bai, J. Shi and Y. Zhu, RSC Adv., 2019, 9, 5512-5520.
37 M. Tachihara, T. Kiriu, A. Hata, Y. Hatakeyama, K. Nakata, T. Nagano, M. Yamamoto, K. Kobayashi, H. Ohnishi and N. Katakami, Cancer Manage. Res., 2019, 11, 7135.

38 P. Correale, M. G. Cusi, M. T. Del Vecchio, A. Aquino, S. Prete, K. Y. Tsang, L. Micheli, C. Nencini, M. La Placa and F. Montagnani, J. Immunol., 2005, 175, 820-828.

39 H. H. Soliman, OncoTargets Ther., 2017, 10, 101.

40 G. V. Shurin, N. Amina and M. R. Shurin, Dendritic Cells in Cancer, Springer, 2009, pp. 201-216.

41 X. Shi and X. Sun, Cancer Chemother. Pharmacol., 2017, 80, 909-917. 